\title{
Editorial
}

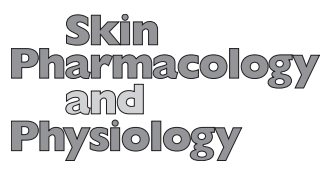

\section{This Issue at a Glance}

The summer is over, or almost over. The vacation time with some extra moments to relax, to enjoy locations different from our daily routine might have inspired you for additional reading and new ideas. The present issue of our journal brings you the following subjects:

Schäfer-Korting et al. (Skin Pharmacol Physiol 2008; 21:203-210) showed that the high efficacy of short-term treatment with terbinafine in patients with tinea pedis is possible due to its fungicidal activity coupled with a distinct reservoir formation in the upper layers of the epidermis.

Telgenhoff et al. (Skin Pharmacol Physiol 2008;21:211217) were able to demonstrate that all-trans-retinoic acid increases the expression of claudin 2 in keratinocytes in a dose-dependent manner. The discovery of claudin 2 transcript and protein in the skin might be of importance in epidermal differentiation, barrier function and pathological conditions.

In the original work of Nicoli et al. (Skin Pharmacol Physiol 2008;21:218-226), rabbit ear skin showed a similar stratum corneum thickness compared to pig skin although the viable epidermis has a different structure. The lipid composition of rabbit stratum corneum was similar to pig stratum corneum but was characterized by a lower content of ceramides and a higher content of cholesterol esters and triglycerides. Differences were seen for hydrophilic compounds, probably because of the higher lipophilicity of its stratum corneum.

$\left[{ }^{3} \mathrm{H}\right]$ thymidine incorporation and apoptosis after fluorescein diacetate/trypan blue staining was used in the study published by Popadic et al. (Skin Pharmacol Physi- ol 2008;21:227-234). All tested agents exerted a dose-dependent inhibition of keratinocyte proliferation. The observed effect of cholecalciferol and ergocalciferol, but not retinoids, involved the induction of apoptotic cell death.

Shibayama et al. (Skin Pharmacol Physiol 2008;21: 235-243) used diffusion cell and dynamic systems as assay methods for permeation and accumulation. The authors studied permeation and metabolism of a novel ascorbic acid derivate. They state that it is advantageous to use two test methods. The diffusion cell system is superior in terms of the fewness of error between skin models, and suitable for an examination of the time course of permeation and metabolism with the same skin model.

Finally a back-to-back paper to the publication by Fluhr et al. (Skin Pharmacol Physiol 2008;21:124-135) from the special edition reporting from the ISP meeting in August 2007 concludes this issue: Basketter et al. (Skin Pharmacol Physiol 2008;21:191-202) report a murine test, the local lymph node assay, as a validated replacement for the guinea pig tests. Despite the recent introduction of in vitro methods for the identification of sensitizing chemicals, the local lymph node assay results can be used as the starting point for a quantitative risk assessment. The quantitative risk assessment is aimed to identify the safe use thresholds for any potential skin sensitizer.

We hope you will enjoy the reading of this issue inspiring you for your daily work and eventually for further research.

Joachim Fluhr, President of the ISP Jürgen Lademann, Editor of the Journal

\begin{tabular}{ll}
\hline KARGER & ( 2008 S. Karger AG, Basel \\
1660-5527/08/0214-0190\$24.50/0 \\
$\begin{array}{l}\text { E-Mail karger@karger.ch } \\
\text { www.karger.com }\end{array}$ & $\begin{array}{l}\text { Accessible online at: } \\
\text { www.karger.com/spp }\end{array}$
\end{tabular}

